\title{
Effects of copper on development and survival rate of Paphia malabarica Chemnitz larvae under low saline condition
}

\author{
R. Gireesh • C. P. Gopinathan
}

Received: 28 February 2008 / Accepted: 11 June 2008

(C) Springer Science + Business Media B.V. 2008

\begin{abstract}
Venerid clam, Paphia malabarica Chemnitz, is the commercially exploited species distributed exclusively in Vembanad Lake and Ashtamudi estuary, along the south west coast of India. In this study, the survival rate and development of $P$. malabarica larvae were studied for 3 days in ambient salinity (33), copper $(2.5 \mu \mathrm{g}$ $\mathrm{Cu}^{2+} \mathrm{l}^{-1}$ ), reduced salinities (25 and 20) and a combination of copper in low salinities. No significant differences were found in larval development between treatments. The survival rates decreased considerably with low salinities although the combination of copper and low salinity gave synergistic effects. The reduced survival in low salinities would limit population growth of this species in estuarine areas experiencing low salinities and also explains the absence of larval settlement on habitats close to harbors or river mouths.
\end{abstract}

Keywords Copper - Development .

Paphia malabarica larvae $\cdot$ Salinity $\cdot$ Survival rate

R. Gireesh · C. P. Gopinathan

Central Marine Fisheries Research Institute, Kochi,

Kerala, India

R. Gireesh $(\bowtie)$

Biological Oceanography, National Institute of

Oceanography, Kochi, Kerala, 682018, India

e-mail: girmsr@gmail.com

\section{Introduction}

Salinity is an important abiotic factor that limits growth and survival of marine organisms, especially in coastal waters where light dependant sessile invertebrates inhabits. Copper is an anthropogenic pollutant known to be harmful in aquatic environment and several sources such as coastal runoffs and anti-fouling paint affects non-target organisms (Peters et al. 1997). Short neck clam, Paphia malabarica (Family: Veneridae) is widely distributed in the Vembanad Lake and Ashtamudi estuary, south west coast of India.

The natural population of $P$. malabarica has been depleted due to commercial exploitation and habitat degradation (Appukuttan 1996). They are hermaphrodites and breed throughout the year although the natural recruitment is low. The larvae are planktonic after fertilization and settle within two weeks as spat and metamorphose into juvenile clams approximately within ten days. Studies on spat production and sea ranching of this species have been carried out (Narasimham 1993). However, ecotoxicological studies on clam larvae are lacking despite the fact that the susceptible larval stage plays an important role in the recruitment to the fishing population. The purpose of the present study was to determine larval survival and development of $P$. malabarica when exposed to medium containing copper $\left(2.5 \mu \mathrm{g} \mathrm{Cu} 2^{+} 1^{-1}\right)$, low salinity (25 and 20) and in low saline medium 
containing copper. This will help to monitor and improve the water quality while larval rearing and spat production of P.malabarica in a hatchery system.

\section{Materials and methods}

The study was performed at Hatchery complex of Central Marine Fisheries Research Institute, Kochi, where the larvae of $P$. malabarica were produced, by induced spawning, and reared following the techniques described by Muthiah et al. (1992). When the larvae were three days old, the experiments were started with 500 larvae in $500 \mathrm{ml}$ filtered aerated seawater (ambient salinity was 33). Six replicates were maintained for each treatment and for copper exposures; a nominal concentration of $2.5 \mu \mathrm{g} \mathrm{Cu} 2^{+} 1^{-1}$ was used. The larvae were kept inside the laboratory under constant conditions (temperature $28^{\circ} \mathrm{C}$ and irradiance $150 \mu \mathrm{E} / \mathrm{m}^{2}, 12 \mathrm{~h}$ light-cycle) and were fed Isochrysis galbana $\left(5 \times 10^{4} \mathrm{cells} / \mathrm{ml}\right)$ once a day. After three days of exposure, the larval (umbo, veliger, veliger with foot developed) samples were washed with filtered seawater and pipetted to a graduated beaker. Seawater was added to bring the volume to $500 \mathrm{ml}$ and total larvae were determined by counting five $0.5 \mathrm{ml}$ samples and developmental stages were observed under a stereo microscope. Cochran's test $(p<0.05)$ was used to analyse the homogeneous variance of the data, One-way
ANOVA and Tukey's post-hoc test were used for further statistical analysis.

\section{Results}

The control larvae at ambient salinity 33 had the highest survival rate, $3.9 \%$, whereas, copperexposed larvae showed a small decrease in survival rate to $3.4 \%$. Salinity of 25 affected the survival rate negatively by $33 \%$ to $2.0 \%$ and salinity 20 by $57.1 \%$ to $1.1 \%$. Synergistic effects were shown for the combination of reduced salinity and copper, where survival rate decreased to $1.0 \%$ compared to control $(P=0.0001)$ (Fig. 1). The larval development observation did not display any significant differences between treatments (Fig. 2). But, a larger proportion of larvae were still free swimming after three days of exposure irrespective of treatment compared to control, an increase ranging between $45-65 \%$.

\section{Discussion and conclusion}

The result indicates that decreased salinity is a crucial stress factor for P. malabarica larvae and comparable to a similar earlier study by the authors with salinity and $\mathrm{pH}$ as factors (Gireesh and Gopinathan 2004). Consequently, the clam reproduction might fail during the monsoon period since, large-scale fresh water influx leads to
Fig. 1 Survival rate of larvae after 3 days of exposure: $C=$ Salinity 33 , $\mathrm{Cu}=2.5 \mu \mathrm{g} \mathrm{Cu} 2+\mathrm{L}^{-1}$, $S 25=$ Salinity $25, S 20=$ Salinity 20 and $\mathrm{Cu} 2++$ Salinity 25. Error and asterisks represent significant differences from control. ** $p<0.01$; *** $p<0.001 . n=6$

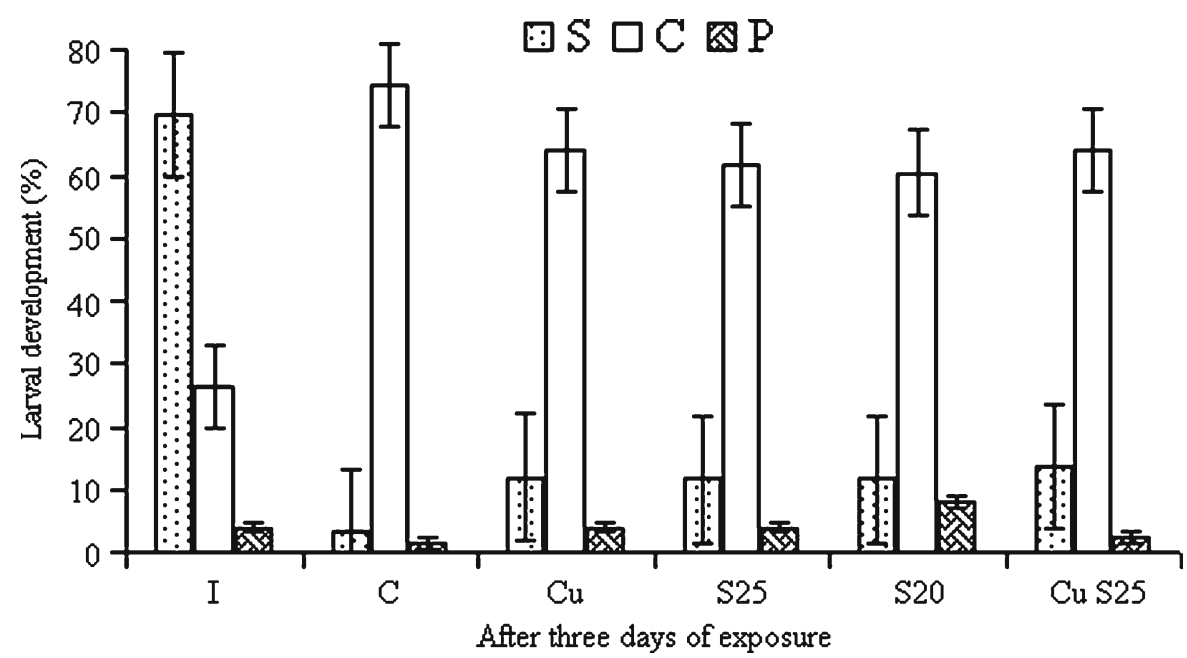


Fig. 2 Larval

development, where $I$ is the allotment of the development day, when the experiment started and the rest after 3 days of exposure. $S=$

Swimming, $C=$ crawling and $P=$ foot developed. Error bars represent SE, $n=6$

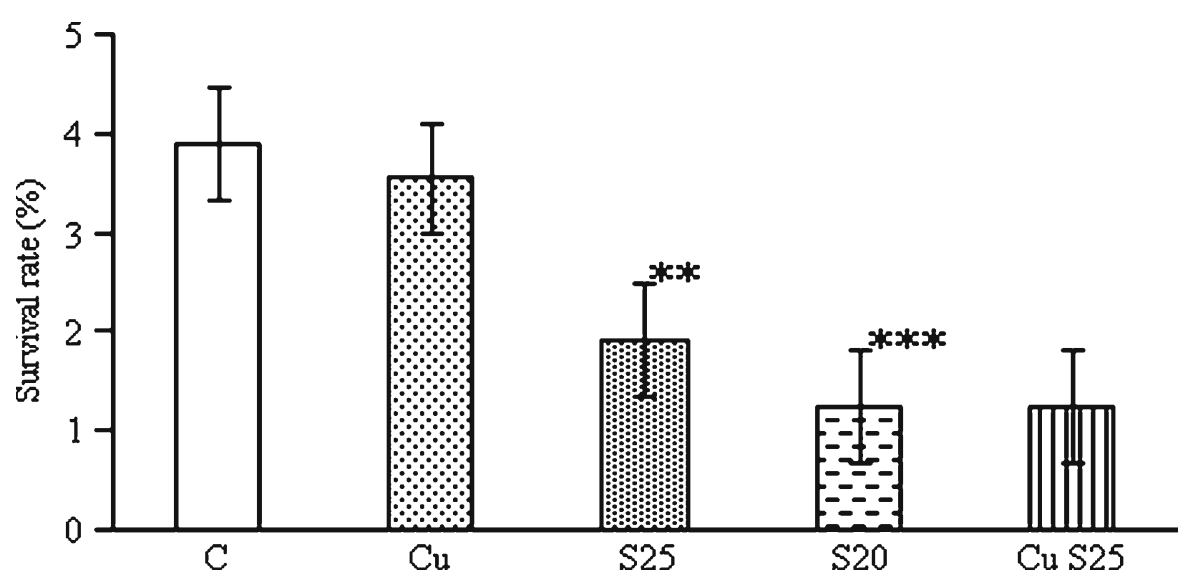

more pronounced salinity drops. Ecotoxicological studies on clams have mostly been carried out on juveniles (Blidberg et al. 1999; Elfwing et al. 2002), where both copper $\left(5 \mu \mathrm{g} \mathrm{Cu} 2^{+} 1^{-1}\right)$ and low salinity have been shown to be sub lethal but negatively affect the physiological performance. However, copper concentrations much higher than this has been reported in reef waters (Peters et al. 1997). It is very likely that copper in higher concentrations than investigated in this study may further increase the mortality in $P$. malabarica larvae.

Larval stages such as the swimming veliger larvae, the crawling larval stage where the larvae searching for a suitable substrate for settlement and the pediveliger larvae ready to undergo metamorphosis become a spat within ten days. No significant dissimilation in stages between treatments was found in the present study but there was common tendency for an increase in number of swimming veliger larvae i.e. delayed development compared to control. Inhibition in invertebrate larval metamorphosis, when larvae exposed to copper as well as other contaminants has been reported (Negri and Heyward 2001; Lyons et al. 2002). The transition from one stage to the next stage is demanding for the larvae and additional stress factors can cause delay in the developmental process, causing possibly high mortality.

Stress factors seldom act alone and reduced salinity in combination with other chemical contamination is a common phenomenon in tropical coastal areas. Here it is monitored that a minor reduction in salinity together with a low dose of a Copper caused effects and this may explain the absence of clams close to Lake mouths. Natural recruitment of clams is normally low despite their high fecundity. This makes the larval stage especially susceptible to environmental changes, which in turn could lead to decreasing populations. Further ecotoxicological studies on larvae and juveniles under various environmental conditions are necessary to get a comprehensive picture of ecological requirements. This will help to improve the status and conservation of this species.

Acknowledgements The first author acknowledges the Department of Ocean Development for the award of Research Assistantship. We are grateful to the Director, CMFRI for providing required facilities.

\section{References}

Appukuttan, K. K. (1996). Short neck clam fishery in Ashtamudi Estuary. Sea Food Export Journal, 27(1), 13-20. 17-24, Oct.

Blidberg, E., Elfwing, T., \& Tedengren, M. (1999). Physiological responses of the fluted giant clam, Tridacna squamosa, exposed to decreased irradiance and reduced salinity. Phuket Marine Biology Special Publication, 19, 85-91.

Elfwing, T., Blidberg, E., \& Tedengren, M. (2002). Physiological responses to copper in giant clams: A comparison of two methods in revealing effects on photosynthesis in zooxanthellae. Marine Environmental Research, 54, 147-155.

Gireesh, R., \& Gopinathan, C. P. (2004). Effect of salinity and $\mathrm{pH}$ for the larval development and spat production of Paphia malabarica. Journal of Marine Biological Association of India, 46(2), 146-153.

Lyons, B. P., Pascoe, C. K., \& McFadzen, I. R. B. (2002). Phototoxicity of pyrene and benzo[a]pyrene to embryo-larval stages of the pacific oyster Crassostrea gigas. Marine Environmental Research, 54, 627-631. 
Muthiah, P., Narasimham, K. A., Gopinathan, C. P., \& Sundararajan, D. (1992). Larval rearing spat production and juvenile growth of the blood clam Anadara granosa. Journal of Marine Biological Association of India, 34(1\&2), 138-143.

Narasimham, K. A. (1993). Ranching of clams in the Ashtamudi Lake. Marine Fisheries Information Series, 124, 14-15.
Negri, A. P., \& Heyward, A. J. (2001). Inhibition of coral fertilization and larval metamorphosis by tributyltin and copper. Marine Environmental Research, 51, 17-27.

Peters, E. C., Gassman, N. J., Firman, J. C., Richmond, R. H., \& Power, E. A. (1997). Ecotoxicology of tropical marine ecosystems. Environmental Toxicology and Chemistry, 16, 12-40. 